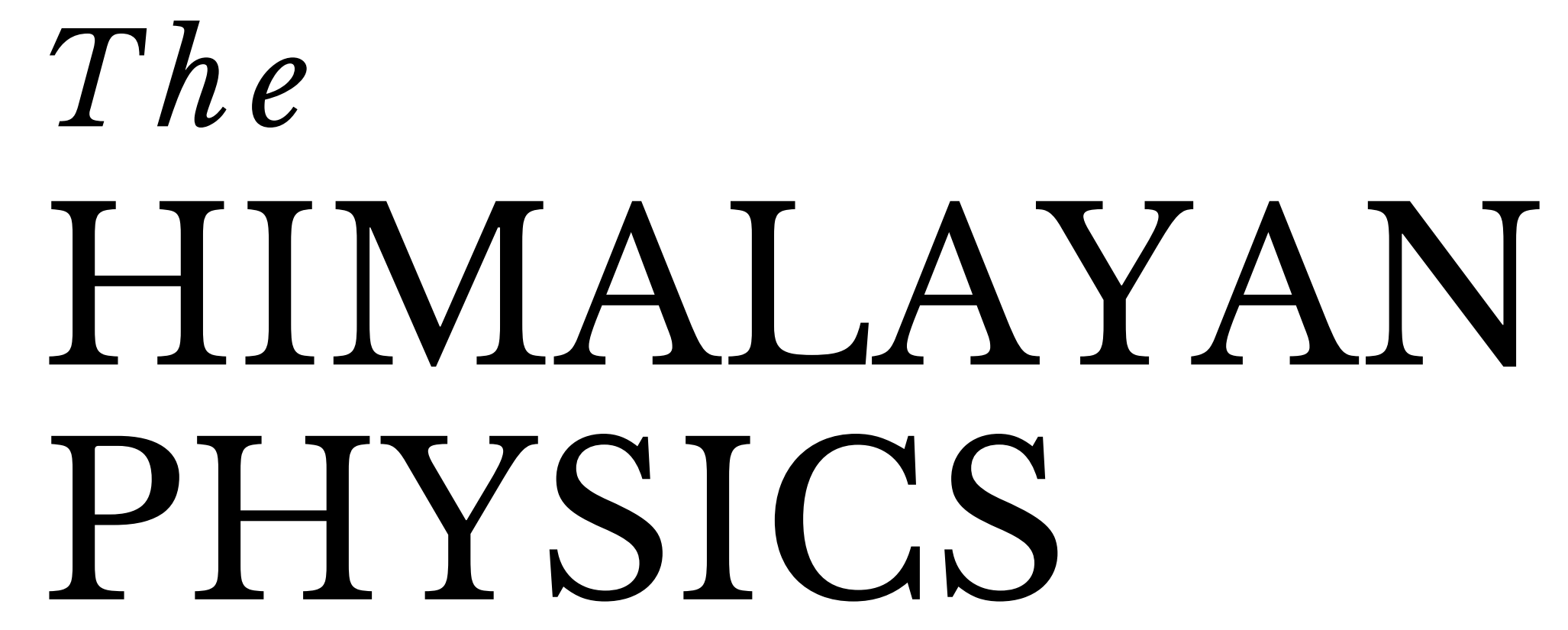

A peer-reviewed Journal of Physics

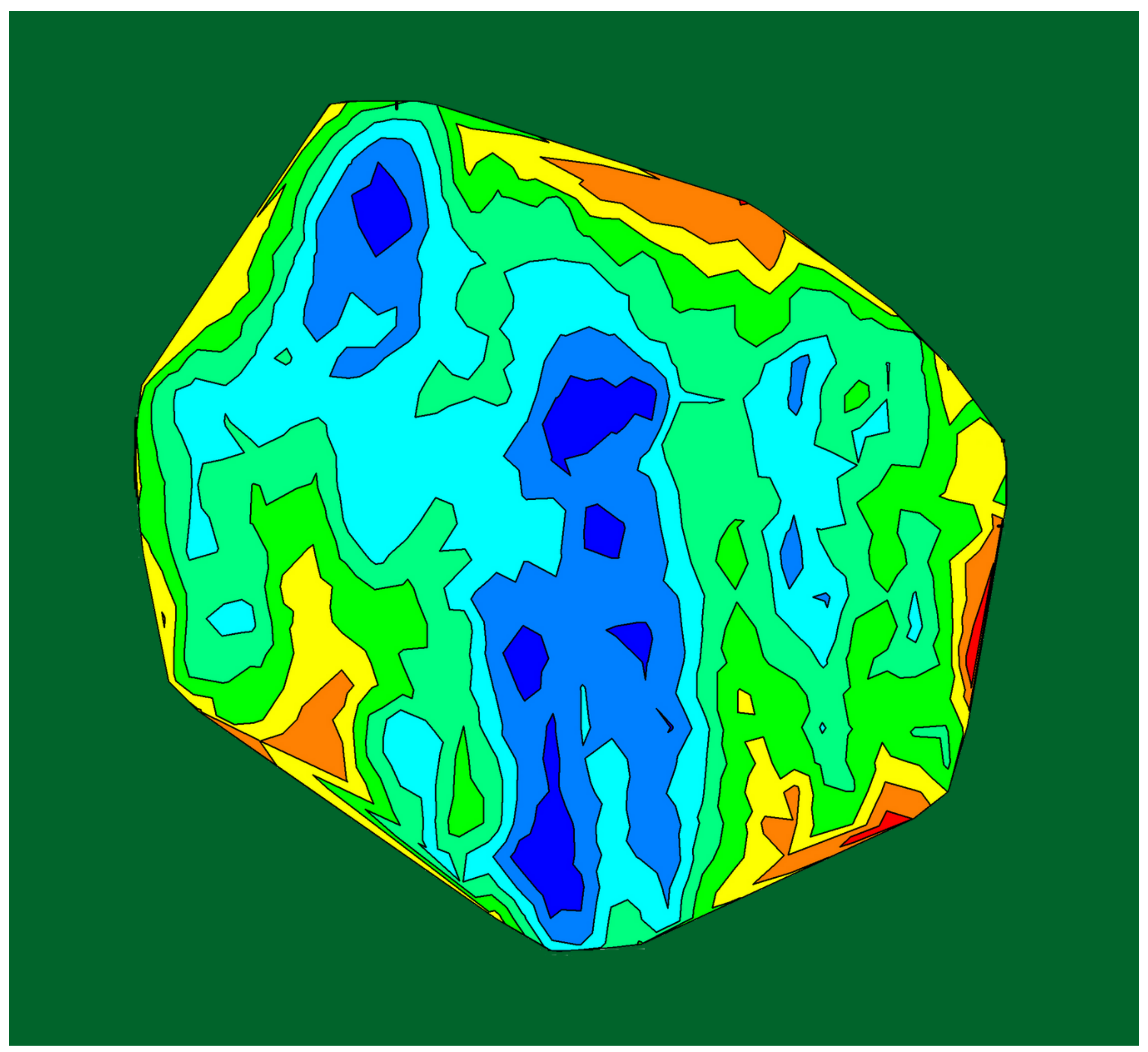

Department of Physics, Prithvi Narayan Campus, Pokhara Nepal Physical Society, Western Chapter, Pokhara 


\section{Publisher}

Department of Physics, Prithvinarayan Campus, Pokhara Nepal Physical Society, Western Chapter, Pokhara

\section{The Himalayan Physics}

Volume 9, December 2020

ISSN 2542-2545

The Himalayan Physics (HimPhys) is an open access peer-reviewed journal that publishes quality articles which make innovative contributions in all areas of Physics. HimPhys is published annually by Nepal Physical Society (Western Regional Chapter), and Department of Physics, Prithvi Narayan Campus, Pokhara. The goal of this journal is to bring together researchers and practitioners from academia in Nepal and abroad to focus on advanced techniques and explore new avenues in all areas of physical sciences and establishing new collaborations with physics community in Nepal.

\section{Chief Editor}

Kapil Adhikari

\section{Associate Editor \\ Aabiskar Bhusal}

(C)2020, Publishers. All rights reserved.

This publication is in copyright. Subject to statutory exception and to the provisions of relevant collective licensing agreements, no reproduction of any part may take place without written permission of the publishers.

Cover: Contour map of dust mass. (C) Mijas Tiwari. Printed from article in the current issue, with permission. 


\section{The HIMALAYAN PHYSICS}

A peer-reviewed Journal of Physics

\section{Chief Editor}

Kapil Adhikari

Associate Editor

Aabiskar Bhusal

\section{Publisher}

Department of Physics, Prithvi Narayan Campus, Pokhara Nepal Physical Society, Western Chapter, Pokhara 


\section{Nepal Physical Society Western Regional Chapter Pokhara, Nepal}

\section{President}

Min Raj Lamsal

Immediate Past President

Jeevan Regmi

Vice-President

Sundar Prasad Dhakal

Secretary

Ravi Karki

Treasurer

Dipak Adhikari

Joint Secretary

Sujan Lamsal

Editorial Member

Kapil Adhikari

Members

Amrit Dhakal

Laxman Thapa

Laxman Timilsina

Narayan Prasad Bhandari

Pradeep Subedi

Advisory Board

Prof. Dr. Pradip K. Bhattarai

Pabitra Mani Poudyal

Surya Bahadur G.C.

Parashu Ram Poudel

Prof. Dr. Shovakanta Lamichhane

Kul Prasad Dahal

Dr. Krishna Raj Adhikari

Ram Sajile Verma 


\section{Himalayan Physics Vol-9 (2020)}

\section{TABLE OF CONTENTS}

Metal Organic Frameworks(MOFs) as efficient carrier for targeted nanodrug delivery

R. Karki, D. Adhikari, K. Adhikari, N. Pantha

A Density Functional Theory Study on Paracetamol-Oxalic Acid Co-Crystal

P. Paudel, K.R. Adhikari, K. Adhikari

First-principles study of $\mathrm{C}$ cites vacancy defects in water adsorbed graphene

H.K. Neupane, N.P. Adhikari

Diusion of fructose in water: a molecular dynamics study

S. Bhusal, N. Pantha

Study of aecting factors of meteorological parameters on solar radiation on Pokhara P.M. Shrestha, J. Regmi, U. Joshi, K.N. Poudyal, N.P. Chapagain, I.B. Karki

Variation of mean value of velocity of ion with dierent obliqueness of magnetized plasma sheath

B.R. Adhikari, H.P. Lamichhane, R. Khanal

Study of dust properties of two far infrared cavities nearby asymptotic giant branch stars under infrared astronomical satellite maps

M. Tiwari, S.P. Gautam, A. Silwal, S. Subedi, A. Paudel, A. K. Jha

An experimental study on irradiated interface of silicon

M.R. Lamsal

Calculation of energy loss of proton beam on thyroid tumor

K. Giri, B. Paudel, B.R. Gautam

Study of noise level status at dierent rice mills in Surkhet Valley, Nepal

D.R. Paudel, H.N. Baral

Elliptically polarized laser assisted elastic electron-hydrogen atom collision and differential scattering cross-section

K. Yadav, S.P. Gupta, J.J. Nakarmi

Geodynamics of Gorkha earthquake (Mw 7.9) and its aftershocks

R.K. Tiwari and H. Paudyal 


\title{
Study of noise level status at different rice mills in Surkhet Valley, Nepal
}

\author{
Research Article
}

\author{
Dharma Raj Paudel ${ }^{1 *}$, Hom Nath Baral ${ }^{1}$ \\ 1 Central Campus of Science and Technology, Mid-Western University, Birendranagar, Surkhet, Nepal
}

\begin{abstract}
Noise is an unwanted sound. High-intensity noise has a detrimental effect on the health conditions. This study aims to measure noise intensity inside different rice mills in Surkhet valley. Rice mills are spread all over Nepal from village to town. They are among the noisiest environment. Twelve mills are selected at different locations inside the valley. Noise intensities are determined by using a sound-level meter and the health conditions of the workers are concluded using a questionnaire technique. The study shows that noise level status is well above the recommended level set by the World Health Organization (WHO). It also concludes statistically that high intensity of sound causes hearing problems in workers.
\end{abstract}

Keywords: Rice Mill • dB(A) • Noise • Sound Level Meter • WHO

\section{Introduction}

Noise is an unwanted sound that is a threat to health and well-being [1]. Therefore, it becomes pollution like air pollution, water pollution, etc. Noise exposure to the workers inside their workplaces might cause longterm health problems; occupational diseases [2]. Therefore, inside the factory- like rice mills where workers are exposed to the high-intensity sound for a long time may cause health-related problems. Workers who are exposed to the high intensity of industrial noise for 5-30 years may show increased blood pressure as well as increased risk for hypertension [3]. Noise exposure changes the function of organs and systems while acute noise exposure can result in an increase in blood pressure, heart rate with cardiac output [4].

High-intensity occupational noise is a problem in all parts of the world. In the United States of America, more than 30 million workers are exposed to the noise levels defined as hazardous by the WHO [3]. This might be a serious issue in developing countries because industrialization does not always care about safety measures.

Due to the high-intensity noise, workers developed hearing loss in the first 10 years of exposure and slight progress in the following years [5]. The prevalence of severe-noise induced hearing loss was 65 percent in the noisy plant compared to $47 \%$ in a less noisy plant [6]. Thus, the study of occupational noise levels of the workers has great importance.

The measure of the noise level is generally carried out in three scales [7]:

\footnotetext{
* Corresponding Author: avipaudel1983@gmail.com
} 


\section{- Sound pressure level (SPL)}

It is a measure of air vibrations that produces sound and is measured on a logarithmic scale with unit $\operatorname{decibels}(\mathrm{dB})$.

\section{- Sound level}

The sound levels are the sound pressure levels accustomed to a weighing to signify the varying sensitivity of the human ear to various frequencies and sound pressure. It is used generally to measure the human response to noise [8]. Sound levels are generally expressed as A-weighted sound pressure levels and expressed in units of $\mathrm{dB}(\mathrm{A})$.

\section{- Equivalent sound levels}

When sound level fluctuates in time, the equivalent sound level can be measured over a specific time period. In this regard, the A-weighted sound level is averaged over a period of time (T) and denoted as $L_{A e q, T}$. The common time period in occupational studies is 8 hour and the sound level are denoted by symbol $L_{A e q, 8 h}$.

\section{Recommendations Levels}

Several organizations have established some regulations for the safety of workers. EU Directive 2003/10/EC sets the limit of the exposure level $L_{A e q, 8 h r}$ for the worker in an eight-hour working day is to $80 \mathrm{~dB}$ while WHO recommends $L_{A e q, 24 h}$ in a limit of $70 \mathrm{~dB}(\mathrm{~A})$ for preventing hearing loss from the industrial area, indoor and outdoor [3]. Further, the National Institute for Safety and Health has a recommendation limit of 85 dB(A) for 8 hours of noise exposure.

The regulations are generally based on the exposure profile of a typical worker who spends eight hours per day and five days per week. Table 1 shows the noise levels per hour for various time averages and corresponding recommended yearly average exposure value. For example, if the workers are involved in an event that takes place for 1, 2, or 14-hour averages, once a week, an hourly noise exposure level of 85 for them, results to an average yearly exposure of $63 \mathrm{~dB}, 66 \mathrm{~dB}$ and $74 \mathrm{~dB}$ respectively.

Table 1 . The yearly average $L_{A e q}$ obtained from the combination of hourly exposure and the number of hours per week [3].

\begin{tabular}{lccccccc}
\hline \multirow{2}{*}{ Hours of exposure per week } & \multicolumn{7}{c}{ One-hour exposure level in $L_{A e q}$} \\
\cline { 2 - 8 } & 70 & 75 & 80 & 85 & 90 & 95 & 100 \\
\hline 1 & 48 & 53 & 58 & 63 & 68 & 73 & 78 \\
2 & 51 & 56 & 61 & 66 & 71 & 76 & 81 \\
4 & 54 & 59 & 64 & 69 & 74 & 79 & 84 \\
$14(2$ hours per day, 7 days per week) & 59 & 64 & 69 & 74 & 79 & 84 & 89 \\
28 (4 hours per day, 7 days per week) & 62 & 67 & 72 & 77 & 82 & 87 & 92 \\
40 (8 hours per day, 5 days per week) & 64 & 69 & 74 & 79 & 84 & 89 & 94 \\
168 (24 hours per day, 7 days per week) & 70 & 75 & 80 & 85 & 90 & 96 & 100 \\
\hline
\end{tabular}




\section{Rice mills}

The milling process, in general, is accompanied in two stages: removing the husk from paddy and then improving the appearance of the rice by removing the outer brown layer. The first step is called husking while the second stage is called polishing. These two stages are carried out by two large machines called husker and polisher respectively. These machines create a noisy environment inside the mill.

The noise survey carried out in the rice mills in the north-eastern region of India concluded that workrooms of 5 rice mills out of eight had SPLs more than 85 decibel and the normal working periods in the rice mills was about 48 hours/week [9] . This study also pointed out the reasons for high noise in such mills are due to the long flat belt drive, absence of electric motor enclosure along with poor machine maintenance and inadequate acoustic interior design.

\section{Materials and Method}

This study is focused on the measurement of noise levels inside the various rice mills at Surkhet Valley by using a sound level meter device in December 2019. The measurements are carried out at day time between 8 am to $3 \mathrm{pm}$. During the survey, the health conditions of the worker are noted by the interview method through a questionnaire. The data are analyzed using statistical tools with necessary diagrams using SPSS [10].

Table 2. Study sites with their locations and codes.

\begin{tabular}{lllc}
\hline S.N. Name of Rice Mill & Location & Code \\
\hline 1 & Basnet Mill & Birendranagar-7, Kalinchowk & A \\
2 & Narayan Seller Mill & Birendranagar-10, Khajura & B \\
3 & Bandali Khadya Udhyog & Birendranagar-12, Padampur & C \\
4 & Basnet Rice mill & Birendra agar, 7, Kalinchok & D \\
5 & Tika Rice Mill & Birendranagar-11, Pipira & E \\
6 & Kafley Rice Mill & Birendranagar-7, Gurung Chowk & F \\
7 & Simran Rice Mill & Birendranagar-11, Dholdhunga & G \\
8 & Kamal and Santab Rice Mill & Birendranagar-11, Charkune & H \\
9 & Bhairav Rice Mill & Birendranagar-4, Bhairabsthan & I \\
10 & Baraghare Rice Mill & Birendranagar-12, Neware & J \\
11 & Tirupati Rice Mill & Birendranagar-12, Neware & K \\
12 & Regmi Rice Mill & Birendra nagar-12, Neware & L \\
\hline
\end{tabular}

This study adopts a cross-sectional research design. The method of data collection is the primary data collection. The device used for the measurement of the sound intensity is the sound level meter, model no. SL4012. Before collecting the data, study sites are selected. There are altogether 60 rice mills in Surkhet valley. Out of them, $20 \%$ i.e. 12 rice mills are randomly selected for the study. Table 2 shows the rice mills with their locations. For the data analysis, mills are given separate codes.

To collect data, the device is placed inside the mills at a place where workers spend most of the time. It is, generally near the machines. The device is set for slow response mode for $L_{e q}$ measurements. The data are set to measure in A-weighted decibel measurement i.e. $\mathrm{dB}(\mathrm{A})$. The $L_{e q}$ measurements are set at first for 1 minute 
i.e. the device shows the average of $L_{e q}$ data in 1 minute. Then again 10 data are taken by setting device for the 1-hour exposure level $L_{e q}$.

From each mill, 20 data (which consists of ten $L_{e q}$ for 1-minute exposure and 10 for 1-hour exposure) are taken. The $95 \%$ confidence intervals is calculated using SPSS. The health conditions of workers are noted through the interview with them. A questionnaire is formed and they are asked whether they suffer a hearing problem or not.

We set up a hypothesis to test the reliability of the data and also determine whether noise intensity is related to hearing problems

\section{Hypothesis}

The hypotheses which are to be tested are:

- One-hour exposure value increases the reliability of sound level meter than one-minute exposure.

- High exposure value is responsible for workers' hearing problems.

These hypotheses are tested from the statistical analysis using SPSS.

\section{Results and Discussion}

During the survey, it is found that all rice mills consist of mainly three common parts: husker, polisher and stone grinder. All of the mills have zinc-coated roofs, concrete floors and brick walls except the mill $\mathrm{H}$, which has a mud roof.

The noise levels in $L_{e q}$ expressed in $\mathrm{dB}(\mathrm{A})$ along with other parameters are shown in table (3). One-year equivalent exposure levels are approximated according to the table (1). From table (3), it can be noted that the mills D, E and $\mathrm{H}$ have high levels of one-year exposure values i.e. above $80 \mathrm{~dB}(\mathrm{~A})$ and these values are well above the yearly recommended limit $70 \mathrm{~dB}(\mathrm{~A})$. It also shows that the total time spent by workers inside mills does not relate to the hearing problem. However, there is a relation between noise exposure levels and hearing loss problems. When the intensity levels are greater than $90 \mathrm{~dB}(\mathrm{~A})$ both in one minute and 1hour exposure, the workers seem to have the hearing problem.

\section{Statistical Analysis}

After applying the Kolmogorov-Smirnov test for goodness of fit of the normal distribution, it is concluded that data in the Table 3 are normal in nature. 

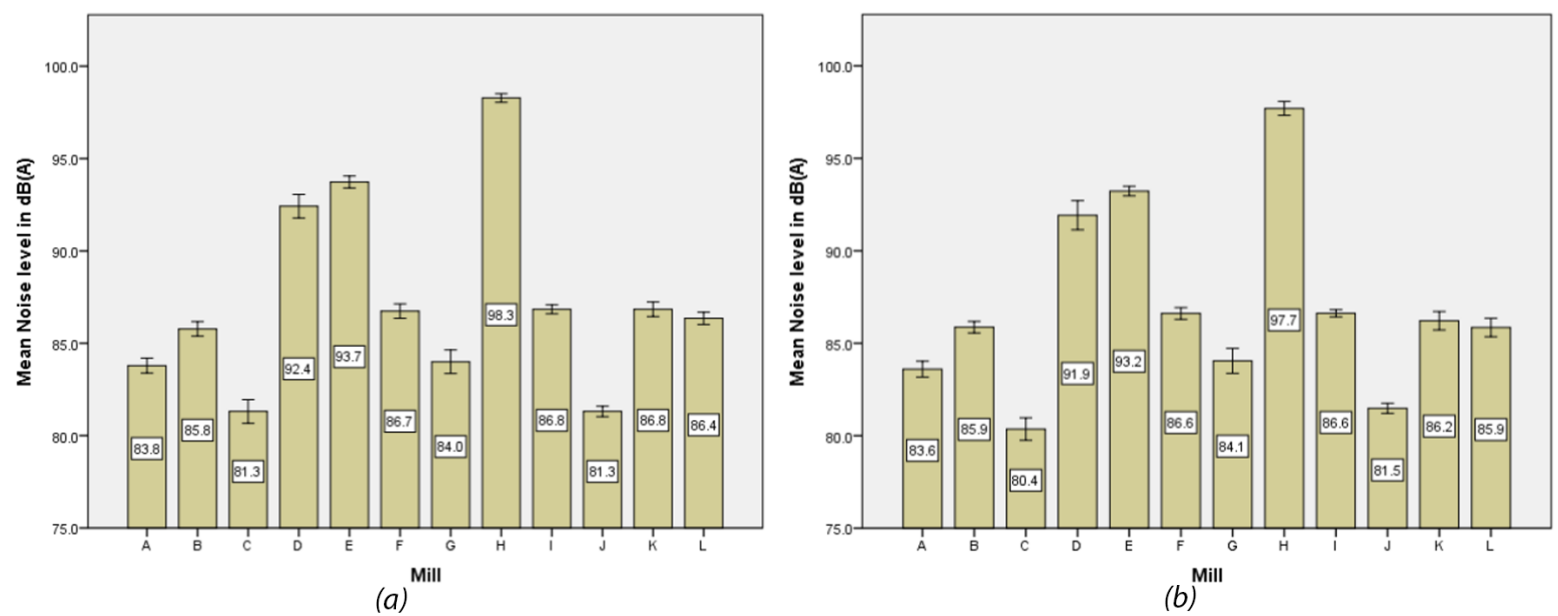

Figure 1. (a) Average of one-minute exposure of different mills showing error bars in $95 \%$ confidence intervals. (b) Average of one-hour exposure of different mills showing error bars in $95 \%$ confidence intervals.

Fig. 1(a) shows that the mill D has a maximum error which means variations in the data taken are maximum. This diagram also shows that high average exposure value is shown by the mill H. Fig. 1(b) represents the average values diagram for one-hour exposure of the workers which is obtained similar to that of Fig. 1(a).

Table 3. Various parameters observed during noise surveys inside mills. One-year exposure levels are determined according to table (1). Exposure values are expressed in $\mathrm{dB}(\mathrm{A})$.

\begin{tabular}{|c|c|c|c|c|c|c|c|c|c|}
\hline S.N. & $\begin{array}{l}\text { Rice } \\
\text { Mill }\end{array}$ & $\begin{array}{l}\text { Avg } 1_{\min } \\
\text { exposure }\end{array}$ & $\begin{array}{l}\text { C.I. for } 1_{\min } \\
\text { exposure }\end{array}$ & $\begin{array}{l}\text { Avg } 1_{\text {hour }} \\
\text { exposure }\end{array}$ & $\begin{array}{l}\text { C.I. for } 1_{\text {hour }} \\
\text { exposure }\end{array}$ & $\begin{array}{l}\text { Avg time exposure } \\
\text { per week(hours) }\end{array}$ & $\begin{array}{l}\text { One-year } \\
\text { exposure }\end{array}$ & $\begin{array}{c}\text { Total time } \\
\text { spent(years) }\end{array}$ & $\begin{array}{l}\text { Hearing } \\
\text { problem }\end{array}$ \\
\hline 1 & $\bar{A}$ & 83.79 & $83.39-84.19$ & 83.60 & $83.16-84.03$ & 40 & 76.5 & 15 & No \\
\hline 2 & B & 85.78 & $85.39-86.17$ & 85.87 & $85.55-86.66$ & 28 & 77 & 16 & No \\
\hline 3 & $\mathrm{C}$ & 81.31 & $80.67-81.95$ & 80.36 & $79.75-80.96$ & 40 & 76.5 & 4 & No \\
\hline 4 & $\mathrm{D}$ & 92.42 & $91.78-93.06$ & 91.92 & $91.13-92.70$ & 28 & 82 & 5 & Yes \\
\hline 5 & $\mathrm{E}$ & 93.73 & $93.40-94.06$ & 93.235 & $92.98-93.48$ & 40 & 86.5 & 26 & Yes \\
\hline 6 & $\mathrm{~F}$ & 86.74 & $86.35-87.13$ & 86.61 & $86.29-86.92$ & 40 & 79 & 8 & No \\
\hline 7 & G & 84.00 & $83.36-84.64$ & 84.05 & $83.37-84.72$ & 40 & 79 & 8 & No \\
\hline 8 & $\mathrm{H}$ & 98.28 & $98.05-98.51$ & 97.70 & $97.32-98.07$ & 40 & 91.5 & 17 & Yes \\
\hline 9 & I & 86.84 & $86.60-87.08$ & 86.62 & $86.41-86.80$ & 40 & 79 & 11 & No \\
\hline 10 & $\mathrm{~J}$ & 81.31 & $81.02-81.60$ & 81.48 & $81.20-81.75$ & 28 & 72 & 2 & No \\
\hline 11 & K & 86.84 & $86.44-87.24$ & 86.22 & $85.72-86.72$ & 40 & 79 & 8 & No \\
\hline 12 & $\mathrm{~L}$ & 86.35 & $86.01-86.69$ & 85.85 & $85.35-86.35$ & 28 & 77 & 2 & No \\
\hline
\end{tabular}

Table 4 shows the comparison of average scores per year of the workers suffering from hearing problems and those not suffering. This table shows that P-value is less than 0.05 , which means the hearing problem is caused due to the high-intensity exposure of sound. Thus, the high level of sound inside the mills causes hearing problems for workers.

Table 4. Comparison of average scores.

\begin{tabular}{clcc}
\hline S.N. & Worker's Condition & Mean Score & P-value \\
\hline 1 & Not suffering & 77.222 & \multirow{2}{*}{0.001} \\
2 & Suffering hearing problem & 86.876 & \\
\hline
\end{tabular}


To know the reliability of the data for setting noise level in one-minute exposure and 1- hour exposure, independent sample test is done, results are shown in Table 5. This shows that in both cases there is no significant difference between mean scores. Also, Levene's test for equality of variances shows that in both cases, there is no significant difference between the variability of the scores. Also, by using a t-test, there is no significant difference between the average score due to 1-minute exposure and 1-hour exposure. This concludes that while taking data by the instrument in the one- minute exposure mode or in the one-hour exposure mode, there is no significant difference.

Table 5. Comparison of average scores.

\begin{tabular}{|c|c|c|c|c|}
\hline \multirow[t]{2}{*}{ S.N. } & \multirow[t]{2}{*}{ Exposure } & \multirow[t]{2}{*}{ Mean } & $\begin{array}{c}\text { Levene's test for equality } \\
\text { of variances }\end{array}$ & $\begin{array}{l}\text { Independent } \\
\text { t-test }\end{array}$ \\
\hline & & & $\mathrm{P}$-value & \\
\hline $\begin{array}{l}1 \\
2\end{array}$ & $\begin{array}{l}1 \text { minute } \\
1 \text { hour }\end{array}$ & $\begin{array}{l}87.283 \\
86.959\end{array}$ & 0.805 & 0.609 \\
\hline
\end{tabular}

\section{Conclusions}

The study of noise surveys in different rice mills of the Surkhet district reveals that workers in all the rice mills are exposed to high noise intensity well above the recommended limit set by WHO. Statistical analysis of the data shows that workers who are exposed to a relatively high level of noise suffer from hearing disorder. Therefore, these mills should apply noise control measures for the safety of their workers' health. This study also concludes that there is no any significant difference of the sound level meter while taking in one-hour exposure mode or one-minute exposure mode.

\section{Recommendation for further study}

Since the health-related problems are only noted by the interview with workers, for more accurate results, it is recommended for the actual medical checkup. Since there is a large number of mills in Surkhet, sample sizes can be increased for better results.

\section{Acknowledgement}

We would like to acknowledge Narayan Adhikari, Professor, Central Department of Physics and Nurul Hoda Khan, Assistant Professor, Central Campus of Science and Technology for the valuable suggestions. 


\section{References}

[1] Goines L, Hagler L. Noise pollution: a modern plague. South Med J. 2007;100(3):287-294.

[2] Siskova V, Juricka M. The effect of sound on job performance. In: 2013 IEEE International Conference on Industrial Engineering and Engineering Management. IEEE; 2013. p. 1679-1683.

[3] Organization WH. Environmental noise guidelines for the European region. 2018;.

[4] Münzel T, Sørensen M. Noise pollution and arterial hypertension. European Cardiology Review. $2017 ; 12(1): 26-29$.

[5] Çelik O, Yalçın Ş, Öztürk A. Hearing parameters in noise exposed industrial workers. Auris Nasus Larynx. 1998;25(4):369-375.

[6] Talbott E, Helmkamp J, Mathews K, Kuller L, Cottington E, Redmond G. Occupational noise exposure, noise-induced hearing loss, and the epidemiology of high blood pressure. American journal of epidemiology. $1985 ; 121(4): 501-514$.

[7] Concha-Barrientos M, Steenland K, Prüss-Üstün A, Campbell-Lendrum DH, Corvalán CF, Woodward A, et al. Occupational noise: assessing the burden of disease from work-related hearing impairment at national and local levels. World Health Organization; 2004.

[8] Goodman JR, Grosveld FW. Acoustics and noise control in space crew compartments. National Aeronautics and Space Administration, Johnson Space Center; 2015.

[9] Kumar GP, Dewangan K, Sarkar A, Kumari A, Kar B, et al. Occupational noise in rice mills. Noise and Health. 2008;10(39):55-67.

[10] IBM Corp . IBM SPSS Statistics for Windows. Armonk, NY: IBM Corp;. 